\title{
Amphetamine Conditioned Place Preference in Planarians
}

\author{
Robert B. Raffa ${ }^{{ }^{*}}$, Sumira Shah ${ }^{2}$, Christopher S. Tallarida ${ }^{1,3}$, Scott M. Rawls ${ }^{3}$ \\ ${ }^{1}$ Department of Pharmaceutical Sciences, Temple University School of Pharmacy, Philadelphia, USA \\ ${ }^{2}$ Neuroscience Program, Temple University, Philadelphia, USA \\ ${ }^{3}$ Center for Substance Abuse Research, Temple University School of Medicine, Philadelphia, USA \\ Email: *robert.raffa@temple.edu
}

Received October 6, 2012; revised November 7, 2012; accepted November 15, 2012

\begin{abstract}
Meth- and other amphetamines currently present major drug-abuse concerns. However, the demonstration and study of abuse-related behaviors expressed in animal models is expensive and time-consuming. We previously reported a novel model of conditioned place preference (CPP), which is a standard tool in abuse research, in invertebrates (planarians). In the present study, planarians were tested for light/dark preference, then exposed for 5 min to either $d$-amphetamine or vehicle (water) in light and then re-tested for place preference (light vs dark). The planarians' natural strong preference for dark (15 of 16) was significantly altered by amphetamine experience, such that 12 of 16 preferred the unnatural, but amphetamine-associated, light side. These results extend the demonstration of CPP to this invertebrate species and provide further evidence in support of this model to testing/screening amphetamine-like and possibly other drugs of abuse.
\end{abstract}

Keywords: Amphetamine; Conditioned Place Preference; Drug Abuse; Planaria

\section{Introduction}

As a class, amphetamine psychostimulants have value in a number of therapeutic applications (e.g., for narcolepsy or ADHD (attention-deficit hyperactivity disorder) [1-3]. But they also have potential for abuse [4], with negative health consequences [5]. An extensive body of evidence suggests that the major rewarding/reinforcing effects of psychostimulants such as the amphetamines is related to their ability to inhibit the neuronal reuptake of dopamine, particularly in the mesocorticolimbic pathway [6-9], and other neurotransmitters such as norepinephrine [10] and the excitatory (glutamate) [6-9] and inhibitory (GABA, $\gamma$-aminobutyric acid) [11] amino acids. In addition, there is broad evidence of a functional interaction between the dopamine and endogenous opioid systems, which might play an important role in amphetamine abuse [12-25].

The conditioned place preference (CPP) paradigm is a measure of incentive learning and an indicator of abuse potential [26-30]. Amphetamine-induced CPP has been demonstrated to occur in humans [31]. In animal models, microinjections of amphetamine into nucleus accumbens establishes a CPP, and the effect is attenuated by lesions produced by 6-OHDA (6-hydroxydopamine) [29], or by microinjections into the n. accumbens of $\alpha$-flupenthixol or reserpine [32], which suggests an involvement of the mesolimbic dopamine pathway in this phenomenon. The acquisition of amphetamine CPP is also attenuated by the

*Corresponding author. selective antagonism of the dopamine D1 [33-34] and the D2 [29,33] receptor or dual antagonism of both subtypes [35]. This plus additional evidence suggests that both of dopamine receptor types are involved when dopamine is released by amphetamine during establishment of CPP [36]. For example, null-mutant orphan G protein-coupled receptor 37 (which colocalizes with the dopamine transporter DAT) knockout mice (GPR37-KO) do not respond to the incentive properties in CPP tests [37].

Other neurotransmitters have been suggested to play a role in CPP in addition to dopamine. For example: the selective serotonin (5-HT, 5-hydroxytryptamine) $5-\mathrm{HT}_{2 \mathrm{C}}$ receptor antagonist 6-Chloro-5-ethoxy- $N$-(pyridin-2-yl) indline-1-carboxamide hydrochloride (CEPC) potentiates low-dose amphetamine CPP [38]; amphetamine-induced CPP is attenuated by selective antagonism of the growth hormone secretagogue receptor 1A (GHS-R1A), which suggests an involvement of the central ghrelin signaling system [39]; the selective non-competitive antagonist of the NMDA NR2B ( $N$-methyl-D-aspartate 2B subunit) receptor, rhynchophylline, reverses the expression of amphetamine-induced CPP [40] and additional evidence suggests that an activation of the NMDA receptor and of CaMKII (calcium/calmodulin-dependent protein kinase II) activity are essential for amphetamine-induced CPP [41]; intracerebroventricular administration of oxytocin inhibits the acquisition and facilitates the extinction of methamphetamine-induced CPP [42]; estradiol-treated female rats have enhanced amphetamine-induced CPP 
compared to vehicle-treated ovariectomized rats [43] (an effect possibly related to the known estrogen enhancement of dopamine-mediated behaviors; amphetamineinduced CPP is blocked by an intra-hippocampal (CA3 region) infusion of an inhibitor of Trk (tyrosine kinase) receptor [44]; intra-accumbens injection of a protein kinase $\mathrm{C}$ inhibitor blocks amphetamine-induced CPP in rats [45]; and both pre- and co-injections of diazepam block the formation of amphetamine-induced CPP [46]. There is additional evidence, but it is beyond the scope of the short overview presented here and the present report.

Planarians have the requisite endogenous neurotransmitter systems relevant to a study amphetamine (ab) use (for review see [47]), including dopamine, acetylcholine, and opioids among others [48-55]. Planarians develop a physical dependence to, and display abstinence-induced and antagonist-precipitated withdrawal from, a diverse list of drugs of abuse [56-61]. We recently reported the development of nicotine- [62] and mephedrone- ("bath sat”) induced [63] CPP in planarians.

\section{Materials and Methods}

\subsection{Animals and Drugs}

The planarians (Dugesia dorotocephala) were purchased from Carolina Biological Supply (Burlington, NC). They were acclimated to the laboratory temperature $\left(21^{\circ} \mathrm{C}\right)$ and were tested within two days of receipt. $d$-Amphetamine was obtained from the National Institute of Drug Abuse.

\subsection{Behavioral Testing}

The methodology was similar to that previously reported by us [62,63]. Briefly, dark and light (ambient) sides were created by covering half of the top, bottom, and sides of a $60 \mathrm{~mm}$ diameter petri dish with black paper or tape. Individual planarians were placed at the midline of the dish. The time that the planarian spent in the nonpreferred side (light) over a 5-min interval was determined (the pre-pairing response). Planarians were then conditioned with exposure to $d$-amphetamine (0.001, 0.1, or $1 \mathrm{mM}$ ) for $30 \mathrm{~min}$ in the opposite non-preferred (light) side. Immediately following conditioning, the planarian was placed again at the midline of the petri dish (now half light and half dark) containing vehicle and the amount of time that the planarians spent in the non-preferred side during the 5-min interval was measured.

\section{Results}

Untreated (drug-naïve) planarians spent $89 \%$ of the time in the dark half of the test chamber (petri dish). The effect of 30-minute exposure to $d$-amphetamine on individual planarian light/dark choice is shown in Figure 1. The $0.001 \mathrm{mM}$ dose reduced the preference to only about

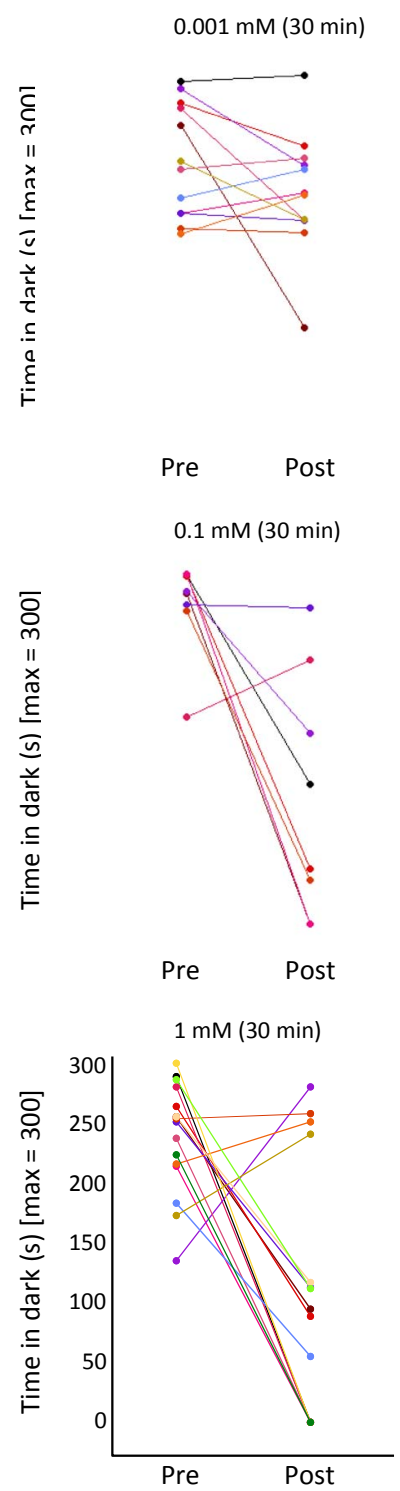

Figure 1. Change in predominant preference for the dark of drug-naïve planarians (Pre) to the dark after 30-min exposure to $d$-amphetamine (Post) $(0.001 \mathrm{mM}$, top graph; 0.1 $\mathrm{mM}$, middle graph; $1 \mathrm{mM}$, bottom graph).

$1 / 2$. The doses of 0.1 and $1 \mathrm{mM}$ reversed the natural preference for dark. Most of the planarians displayed a CPP for the side in which they exposed to $d$-amphetamine, i.e., they spent more time in the light.

The effect of $d$-amphetamine exposure on reversal of planarian light/dark preference choice was dose related. $d$-Amphetamine (0.001, 0.1 , and $1 \mathrm{mM}$ ) exposure during conditioning produced dose-related increase in the time planarians spent in the light (Figure 2). The data are plotted as the mean \pm s.e.m. of the percent of time that planarians spent in the light during the 5-min observation period.

The effect of $d$-amphetamine exposure time on reversal of planarian light/dark preference is shown in Figure 3. 


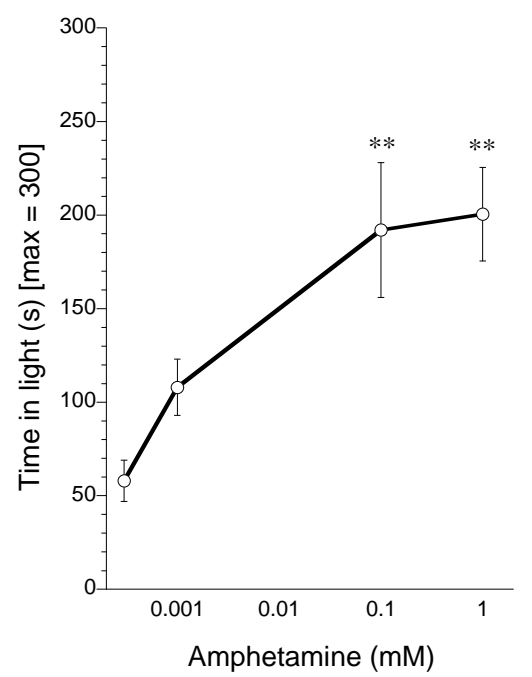

Figure 2. Dose-related change in predominant preference for the dark of planarians. $N=8-16$ planarians per group. ${ }^{* * *} \mathrm{P}<0.01$ (ANOVA df $=\mathbf{5 1}, \mathrm{F}=\mathbf{1 1 . 2}$ ).

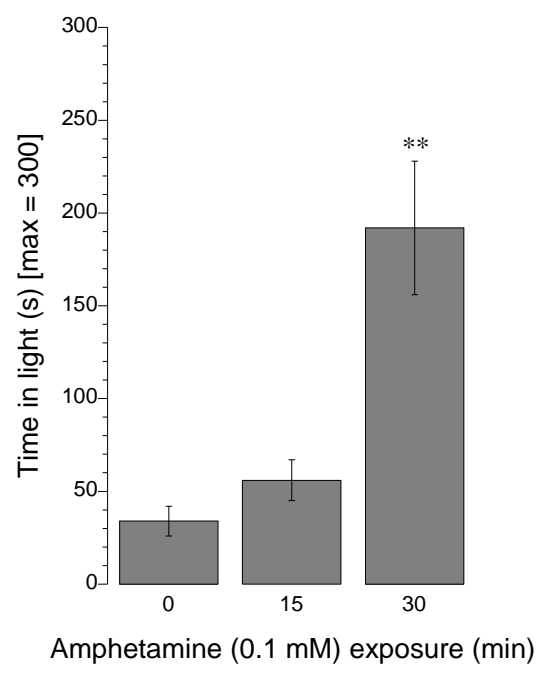

Figure 3. Change in the predominant preference for dark after 30-min exposure to $d$-amphetamine $(0.1 \mathrm{mM}) . \mathrm{N}=8$ 16 planarians per group. ${ }^{* *} \mathrm{P}<0.01$ (ANOVA df $=51, \mathrm{~F}=$ 11.2).

\section{Discussion}

Freely-moving planarians display a strong natural choice for the dark, as in the present study of $\sim 90 \%$ of the time. We previously reported [64] that exposure of planarians to cocaine reverses the strong preference that planarians display for the dark in a simple choice paradigm. That is, when cocaine-naïve planarians were allowed to choose, they spent about $80 \%$ of a 10 -min test period in the dark, similar to the present study. However, when exposed to cocaine $\left(8 \times 10^{-5} \mathrm{M}\right)$, they reversed their preference and spent about $73 \%$ of the 10 -min test period in visible light (source maintained at a constant distance, $12.5 \mathrm{~cm}$ above and perpendicular to the test apparatus). Other factors, such as the ambient light conditions, test $\mathrm{pH}$, directional preference, local differences in test apparatus, etc. were carefully controlled or randomized. The effect was not simply secondary to an increase in spontaneous or druginduced locomotor activity, since cocaine only minimally increases planarian locomotor activity at the highest dose tested [58]. It was also not due merely to a disruption of sensory systems, since the behavior did not revert to a random 50/50 split between light and dark. Hence, the effect appeared to be directly related to cocaine.

Similarly, in the present study drug-naïve planarians displayed a clear preference for light (about 90\%), which is consistent with our previous findings. Exposure of the planarians to $d$-amphetamine $(0.1 \mathrm{mM})$ for 15 minutes reduced the dark-preference to only $\sim 50 \%$ and exposure to amphetamine for 30 minutes inverted the preference to light-demonstrative of a conditioned place preference. This is to our knowledge the first report of the development of CPP to amphetamine in planarians. The demonstration of this phenomenon in planarians is important, because planarians have proven to be a valuable model system for studying drug action and abuse [47]. These results can now form the basis for investigation of other drugs of abuse and a more detailed investigation of the biochemical processes involved.

\section{Acknowledgements}

The authors thank Timothy Shickley, Ph.D., for suggesting Planaria as a model system. This work was supported by NIDA grants DA15378 and P30DA01342 (Ellen M. Unterwald, Ph.D., Temple University School of Medicine, PI).

\section{REFERENCES}

[1] L. Christensen, R. Sasane, P. Hodgkins, C. Harley and S. Tetali, "Pharmacological Treatment Patterns among Patients with Attention-Deficit/Hyperactivity Disorder: Retrospective Claims-Based Analysis of a Managed Care Population,” Current Medical Research Opinion, Vol. 26, 2010, No. 4, pp. 977-989. doi:10.1185/03007991003673617

[2] G. Mattingly, "Lisdexamfetamine Dimesylate: A Prodrug Stimulant for the Treatment of ADHD in Children and Adults," CNS Spectrum, Vol. 15, No. 5, 2010, pp. 315325.

[3] G. Didato and L. Nobili, “Treatment of Narcolepsy,” Expert Reviews Neurotherapy, Vol. 9, No. 6, 2009, pp. 897910. doi:10.1586/ern.09.29

[4] D. Ciccarone, "Stimulant Abuse: Pharmacology, Cocaine, Methamphetamine, Treatment, Attempts at Pharmacotherapy,” Primary Care, Vol. 38, No. 1, 2011, pp. 41-58. doi:10.1016/j.pop.2010.11.004

[5] C. Y. Chen and K. M. Lin, "Health Consequences of Illegal Drug Use,” Current Opinion Psychiatry, Vol. 22, 
No. 3, 2009, pp. 287-292. doi:10.1097/YCO.0b013e32832a2349

[6] M. Gronig, A. Atalla and K. Kuschinsky, "Effects of Dizocilpine [(+)-MK-801] on the Expression of Associative and Non-Associative Sensitization to D-Amphetamine," Naunyn Schmiedebergs Archives Pharmacology, Vol. 369, No. 2, 2004, pp. 228-231. doi:10.1007/s00210-003-0855-8

[7] V. Herzig, E. M. Capuani, K. A. Kovar and W. J. Schmidt, "Effects of MPEP on Expression of Food-, MDMAor Amphetamine-Conditioned Place Preference in Rats," Addiction Biology, Vol. 10, No. 3, 2005, pp. 243-249. doi:10.1080/13556210500223272

[8] S. E. Tan, "Roles of Hippocampal NMDA Receptors and Nucleus Accumbens D1 Receptors in the AmphetamineProduced Conditioned Place Preference in Rats," Brain Research Bulletin, Vol. 77, No. 6, 2008, pp. 412-419. doi:10.1016/j.brainresbull.2008.09.007

[9] T. M. Tzschentke and W. J. Schmidt, "Blockade of Morphine- and Amphetamine-Induced Conditioned Place Preference in the Rat by Riluzole," Neuroscience Letters, Vol. 242, No. 2, 1998, pp. 114-116. doi:10.1016/S0304-3940(98)00023-8

[10] R. Ventura, S. Cabib, A. Alcaro, C. Orsini and S. Puglisi-Allegra, "Norepinephrine in the Prefrontal Cortex Is Critical for Amphetamine-Induced Reward and Mesoaccumbens Dopamine Release," Journal of Neuroscience, Vol. 23, No. 5, 2003, pp. 1879-1885.

[11] B. Halbout, D. Quarta, E. Valerio, C. A. Heidbreder and D. M. Hutcheson, "The GABA-B Positive Modulator GS 39783 Decreases Psychostimulant Conditioned-Reinforcement and Conditioned-Reward," Addiction Biology, Vol. 16, No. 3, 2011, pp. 416-427. doi:10.1111/j.1369-1600.2010.00278.x

[12] J. S. Andrews and S. G. Holtzman, "Effects of Naloxone and Diprenorphine on Amphetamine-Stimulated Behavior in Guinea Pigs and Rats,” Neuropharmacology, Vol. 26, No. 8, 1987, pp. 1115-1120. doi:10.1016/0028-3908(87)90256-5

[13] A. M. Dlugos, A. Hamidovic, C. Hodgkinson, P. H. Shen, D. Goldman, A. A. Palmer and H. de Wit, "OPRM1 Gene Variants Modulate Amphetamine-Induced Euphoria in Humans," Genes and Brain Behavior, Vol. 10, No. 2, 2011, pp. 199-209. doi:10.1111/j.1601-183X.2010.00655.x

[14] M. V. Gonzalez-Nicolini, W. Berglind, K. S. Cole, C. L. Keogh and J. F. McGinty, "Local mu and Delta Opioid Receptors Regulate Amphetamine-Induced Behavior and Neuropeptide mRNA in the Striatum,” Neuroscience, Vol. 121, No. 2, 2003, pp. 387-398. doi:10.1016/S0306-4522(03)00488-3

[15] J. Haggkvist, C. Bjorkholm, P. Steensland, S. Lindholm, J. Franck and B. Schilstrom, "Naltrexone Attenuates Amphetamine-Induced Locomotor Sensitization in the Rat," Addiction Biology, Vol. 16, No. 1, 2011, pp. 20-29. doi:10.1111/j.1369-1600.2009.00199.x

[16] J. Haggkvist, S. Lindholm and J. Franck, “The Opioid Receptor Antagonist Naltrexone Attenuates Reinstatement of Amphetamine Drug-Seeking in the Rat,” Behav- ioral Brain Research, Vol. 197, No. 1, 2009, pp. 219-224. doi:10.1016/j.bbr.2008.08.021

[17] N. Jayaram-Lindstrom, M. Konstenius, S. Eksborg, O. Beck, A. Hammarberg and J. Franck, "Naltrexone Attenuates the Subjective Effects of Amphetamine in Patients with Amphetamine Dependence," Neuropsychopharmacology, Vol. 33, No. 8, 2008, pp. 1856-1863. doi:10.1038/sj.npp.1301572

[18] N. Jayaram-Lindstrom, P. Wennberg, Y. L. Hurd and J. Franck, "Effects of Naltrexone on the Subjective Response to Amphetamine in Healthy Volunteers," Journal of Clinical Psychopharmacology, Vol. 24, No. 6, 2004, pp. 665-669.doi:10.1097/01.jcp.0000144893.29987.e5

[19] C. Jimenez-Gomez, G. Winger, R. L. Dean, D. R. Deaver and J. H. Woods, "Naltrexone Decreases D-Amphetamine and Ethanol Self-Administration in Rhesus Monkeys," Behavioral Pharmacology, Vol. 22, No. 1, 2011, pp. 87 90. doi:10.1097/FBP.0b013e3283423d55

[20] M. F. Olive, H. N. Koenig, M. A. Nannini and C. W. Hodge, "Stimulation of Endorphin Neurotransmission in the Nucleus Accumbens by Ethanol, Cocaine, and Amphetamine," Journal of Neuroscience, Vol. 21, No. 23, 2001, p. RC184

[21] C. A. Schad, J. B. Justice Jr. and S. G. Holtzman, "Endogenous Opioids in Dopaminergic Cell Body Regions Modulate Amphetamine-Induced Increases in Extracellular Dopamine Levels in the Terminal Regions,” Journal of Pharmacology and Experimental Therapeutics, Vol. 300, No. 3, 2002, pp. 932-938. doi:10.1124/jpet.300.3.932

[22] G. J. Schaefer and R. P. Michael, "Interactions of Naloxone with Morphine, Amphetamine and Phencyclidine on Fixed Interval Responding for Intracranial Self-Stimulation in Rats," Psychopharmacology, Vol. 102, No. 2, 1990, pp. 263-268. doi:10.1007/BF02245931

[23] J. T. Winslow and K. A. Miczek, "Naltrexone Blocks Amphetamine-Induced Hyperactivity, but Not Disruption of Social and Agonistic Behavior in Mice and Squirrel Monkeys,” Psychopharmacology, Vol. 96, No. 4, 1988, pp. 493-499. doi:10.1007/BF02180030

[24] J. Wiskerke, D. Schetters, I. E. van Es, Y. van Mourik, B. R. den Hollander, A. N. Schoffelmeer and T. Pattij, "muOpioid Receptors in the Nucleus Accumbens Shell Region Mediate the Effects of Amphetamine on Inhibitory Control but Not Impulsive Choice," Journal of Neuroscience, Vol. 31, No. 1, 2011, pp. 262-272. doi:10.1523/JNEUROSCI.4794-10.2011

[25] J. Haggkvist, S. Lindholm and J. Franck, "The Effect of Naltrexone on Amphetamine-Induced Conditioned Place Preference and Locomotor Behaviour in the Rat," Addiction Biology, Vol. 14, No. 3, 2009, pp. 260-269. doi:10.1111/j.1369-1600.2009.00150.x

[26] A. Ettenberg and C. L. Duvauchelle, "Haloperidol Blocks the Conditioned Place Preferences Induced by Rewarding Brain Stimulation,” Behavioral Neuroscience, Vol. 102, No. 5, 1988, pp. 687-691. doi:10.1037/0735-7044.102.5.687

[27] S. Mithani, M. T. Martin-Iverson, A. G. Phillips and H. C. Fibiger, "The Effects of Haloperidol on Amphetamine- 
and Methylphenidate-Induced Conditioned Place Preferences and Locomotor Activity," Psychopharmacology, Vol. 90, No. 2, 1986, pp. 247-252. doi:10.1007/BF00181251

[28] J. E. Sherman, T. Roberts, S. E. Roskam and E. W. Holman, "Temporal Properties of the Rewarding and Aversive Effects of Amphetamine in Rats," Pharmacology, Biochemistry and Behavior, Vol. 13, No. 4, 1980, pp. 597-599. doi:10.1016/0091-3057(80)90288-9

[29] C. Spyraki, H. C. Fibiger and A. G. Phillips, "Dopaminergic Substrates of Amphetamine-Induced Place Preference Conditioning," Brain Research, Vol. 253, No. 1-2, 1982, pp. 185-193. doi:10.1016/0006-8993(82)90685-0

[30] C. Spyraki, H. C. Fibiger and A. G. Phillips, “Attenuation by Haloperidol of Place Preference Conditioning Using Food Reinforcement," Psychopharmacology, Vol. 77, No. 4, 1982, pp. 379-382. doi:10.1007/BF00432775

[31] E. Childs and H. de Wit, "Amphetamine-Induced Place Preference in Humans,” Biological Psychiatry, Vol. 65, No. 10, 2009, pp. 900-904. doi:10.1016/j.biopsych.2008.11.016

[32] N. Hiroi and N. M. White, "The Reserpine-Sensitive Dopamine Pool Mediates (+)-Amphetamine-Conditioned Reward in the Place Preference Paradigm,” Brain Research, Vol. 510, No. 1, 1990, pp. 33-42. doi:10.1016/0006-8993(90)90724-P

[33] D. C. Hoffman and R. J. Beninger, "The Effects of Selective Dopamine D1 or D2 Receptor Antagonists on the Establishment of Agonist-Induced Place Conditioning in Rats," Pharmacology, Biochemistry and Behavior, Vol. 33, No. 2, 1989, pp. 273-279. doi:10.1016/0091-3057(89)90499-1

[34] P. Leone and G. Di Chiara, "Blockade of D-1 Receptors by SCH 23390 Antagonizes Morphine- and Amphetamine-Induced Place Preference Conditioning," European Journal of Pharmacology, Vol. 135, No. 2, 1987, pp. 251-254. doi:10.1016/0014-2999(87)90621-2

[35] R. M. Liao, "Development of Conditioned Place Preference Induced by Intra-Accumbens Infusion of Amphetamine Is Attenuated by Co-Infusion of Dopamine D1 and D2 Receptor Antagonists,” Pharmacology, Biochemistry and Behavior, Vol. 89, No. 3, 2008, pp. 367-373. doi:10.1016/j.pbb.2008.01.009

[36] N. Hiroi and N. M. White, "The Amphetamine Conditioned Place Preference: Differential Involvement of Dopamine Receptor Subtypes and Two Dopaminergic Terminal Areas,” Brain Research, Vol. 552, No. 1, 1991, pp. 141-152. doi:10.1016/0006-8993(91)90672-I

[37] D. Marazziti, C. Di Pietro, S. Mandillo, E. Golini, R. Matteoni and G. P. Tocchini-Valentini, "Absence of the GPR37/PAEL Receptor Impairs Striatal Akt and ERK2 Phosphorylation, DeltaFosB Expression, and Conditioned Place Preference to Amphetamine and Cocaine,” FASEB Journal, Vol. 25, No. 6, 2011, pp. 2071-2081. doi:10.1096/fj.10-175737

[38] J. D. McCorvy, A. A. Harland, R. Maglathlin and D. E. Nichols, “A 5-HT(2C) Receptor Antagonist Potentiates a Low Dose Amphetamine-Induced Conditioned Place Preference,” Neuroscience Letters, Vol. 505, No. 1, 2011, pp.
10-13. doi:10.1016/j.neulet.2011.07.036

[39] E. Jerlhag, E. Egecioglu, S. L. Dickson and J. A. Engel, "Ghrelin Receptor Antagonism Attenuates Cocaine- and Amphetamine-Induced Locomotor Stimulation, Accumbal Dopamine Release, and Conditioned Place Preference,” Psychopharmacology, Vol. 211, No. 4, 2010, pp. 415- 422. doi:10.1007/s00213-010-1907-7

[40] J. Y. Zhou, Z. X. Mo and S. W. Zhou, "Rhynchophylline Down-Regulates NR2B Expression in Cortex and Hippocampal CA1 Area of Amphetamine-Induced Conditioned Place Preference Rat,” Archives of Pharmacal Research, Vol. 33, No. 4, 2010, pp. 557-565. doi:10.1007/s12272-010-0410-3

[41] S. Sakurai, L. Yu and S. E. Tan, "Roles of Hippocampal N-methyl-D-aspartate Receptors and Calcium-Calmodulin-Dependent Protein Kinase II in Amphetamine-produced Conditioned Place Preference in Rats,” Behavioral Pharmacology, Vol. 18, No. 5-6, 2007, pp. 497-506. doi:10.1097/FBP.0b013e3282ee7b62

[42] J. Qi, J. Y. Yang, F. Wang, Y. N. Zhao, M. Song and C. F. $\mathrm{Wu}$, "Effects of Oxytocin on Methamphetamine-Induced Conditioned Place Preference and the Possible Role of Glutamatergic Neurotransmission in the Medial Prefrontal Cortex of Mice in Reinstatement," Neuropharmacology, Vol. 56, No. 5, 2009, pp. 856-865. doi:10.1016/j.neuropharm.2009.01.010

[43] J. L. Silverman and J. I. Koenig, "Evidence for the Involvement of ERbeta and RGS9-2 in 17-Beta Estradiol Enhancement of Amphetamine-Induced Place Preference Behavior,” Hormones and Behavior, Vol. 52, No. 2, 2007, pp. 146-155. doi:10.1016/j.yhbeh.2007.03.017

[44] F. Shen, G. E. Meredith and T. C. Napier, "Amphetamine-Induced Place Preference and Conditioned Motor Sensitization Requires Activation of Tyrosine Kinase Receptors in the Hippocampus," Journal of Neuroscience, Vol. 26, No. 43, 2006, pp. 11041-11051. doi:10.1523/JNEUROSCI.2898-06.2006

[45] H. Aujla and R. J. Beninger, "Intra-Accumbens Protein Kinase C Inhibitor NPC 15437 Blocks AmphetamineProduced Conditioned Place Preference in Rats," Behavioral Brain Research, Vol. 147, No. 1-2, 2003, pp. 41-48. doi:10.1016/S0166-4328(03)00136-0

[46] F. Leri and K. B. Franklin, "Effects of Diazepam on Conditioned Place Preference Induced by Morphine or Amphetamine in the Rat," Psychopharmacology, Vol. 150, No. 4, 2000, pp. 351-360. doi:10.1007/s002130000448

[47] R. B. Raffa and S. M. Rawls, "Planaria: A Model for Drug Action and Abuse,” Landes Bioscience, 2008.

[48] F. R. Buttarelli, F. E. Pontieri, V. Margotta and G. Palladini, “Acetylcholine/Dopamine Interaction in Planaria," Comparative Biochemistry and Physiology Part C Toxicology and Pharmacology, Vol. 125, No. 2, 2000, pp. 225-231.

[49] S. Algeri, A. Carolei, P. Ferretti, C. Gallone, G. Palladini and G. Venturini, "Effects of Dopaminergic Agents on Monoamine Levels and Motor Behaviour in Planaria," Comparative Biochemistry and Physiology Part C Toxicology and Pharmacology, Vol. 74, No. 1, 1983, pp. 27-29. doi:10.1016/0742-8413(83)90142-1 
[50] G. Palladini, S. Ruggeri, F. Stocchi, M. F. De Pandis, G. Venturini and V. Margotta, "A Pharmacological Study of Cocaine Activity in Planaria,” Comparative Biochemistry and Physiology Part C Toxicology and Pharmacology, Vol. 115, No. 1, 1996, pp. 41-45. doi:10.1016/S0742-8413(96)00053-9

[51] F. Passarelli, A. Merante, F. E. Pontieri, V. Margotta, G. Venturini and G. Palladini, "Opioid-Dopamine Interaction in Planaria: A Behavioral Study,” Comparative Biochemistry and Physiology Part C Toxicology and Pharmacology, Vol. 124, No. 1, 1999, pp. 51-55. doi:10.1016/S0742-8413(99)00048-1

[52] P. Ribeiro, F. El-Shehabi and N. Patocka, "Classical Transmitters and Their Receptors in Flatworms," Parasitology, Vol. 131, No. S1, 2005, pp. S19-S40. doi:10.1017/S0031182005008565

[53] G. Venturini, A. Carolei, G. Palladini, V. Margotta and M. G. Lauro, "Radioimmunological and Immunocytochemical Demonstration of Met-Enkephalin in Planaria," Comparative Biochemistry and Physiology Part C Toxicology and Pharmacology, Vol. 74, No. 1, 1983, pp. 23-25. doi:10.1016/0742-8413(83)90141-X

[54] G. Venturini, F. Stocchi, V. Margotta, S. Ruggieri, D. Bravi, P. Bellantuono and G. Palladini, "A Pharmacological Study of Dopaminergic Receptors in Planaria,” Neuropharmacology, Vol. 28, No. 12, 1989, pp. 13771382. doi:10.1016/0028-3908(89)90013-0

[55] J. H. Welsh and L. D. Williams, "Monoamine-Containing Neurons in Planaria," Journal of Comparative Neurology, Vol. 138, No. 1, 1970, pp. 103-115. doi:10.1002/cne.901380108

[56] R. B. Raffa and P. Desai, "Description and Quantification of Cocaine Withdrawal Signs in Planaria,” Brain Research, Vol. 1032, No. 1-2, 2005, pp. 200-202. doi:10.1016/j.brainres.2004.10.052

[57] R. B. Raffa, G. W. Stagliano and S. Umeda, "kappa-Opi- oid Withdrawal in Planaria,” Neuroscience Letters, Vol. 349, No. 3, 2003, pp. 139-142. doi:10.1016/S0304-3940(03)00814-0

[58] R. B. Raffa and J. M. Valdez, "Cocaine Withdrawal in Planaria,” European Journal of Pharmacology, Vol. 430, No. 1, 2001, pp. 143-145. doi:10.1016/S0014-2999(01)01358-9

[59] S. Umeda, G. W. Stagliano and R. B. Raffa, "Cocaine and Kappa-Opioid Withdrawal in Planaria Blocked by D-, but Not L-, Glucose,” Brain Research, Vol. 1018, No. 2, 2004, pp. 181-185. doi:10.1016/j.brainres.2004.05.057

[60] A. L. Rowlands and O. R. Pagan, "Parthenolide Prevents the Expression of Cocaine-Induced Withdrawal Behavior in Planarians," European Journal of Pharmacology, Vol. 583, No. 1, 2008, pp. 170-172. doi:10.1016/j.ejphar.2008.01.012

[61] O. R. Pagan, A. L. Rowlands, M. Azam, K. R. Urban, A. H. Bidja, D. M. Roy, R. B. Feeney and L. K. Afshari, "Reversal of Cocaine-Induced Planarian Behavior by Parthenolide and Related Sesquiterpene Lactones," Pharmacology, Biochemistry and Behavior, Vol. 89, No. 2, 2008 , pp. 160-170. doi:10.1016/j.pbb.2007.12.008

[62] S. M. Rawls, T. Patil, C. S. Tallarida, S. Baron, M. Kim, K. Song, S. Ward and R. B. Raffa, "Nicotine Behavioral Pharmacology: Clues from Planarians," Drug and Alcohol Dependence, Vol. 118, No. 2-3, 2011, pp. 274-279. doi:10.1016/j.drugalcdep.2011.04.001

[63] L. Ramoz, S. Lodi, P. Bhatt, A. B. Reitz, C. Tallarida, R. J. Tallarida, R. B. Raffa and S. M. Rawls, "Mephedrone ('Bath Salt') Pharmacology: Insights from Invertebrates," Neuroscience, Vol. 208, 2012, pp. 79-84. doi:10.1016/j.neuroscience.2012.01.019

[64] R. B. Raffa, C. S. Dasrath and D. R. Brown, "Disruption of a Drug-Induced Choice Behavior by UV Light," Behavioral Pharmacology, Vol. 14, No. 7, 2003, pp. 569571. doi:10.1097/00008877-200311000-00010 